\title{
Research Paper: Relationship of Cognitive Emotion Regulation and Meaning in Life With Health Anxiety Among Emergency Nurses
}

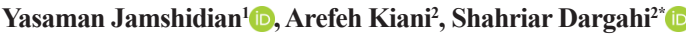

1. Department of Counseling, Faculty of Psychology and Education Sciences, Marvdasht Branch, Islamic Azad University, Marvdasht, Iran. 2. Department of Counseling, Faculty of Psychology and Education Sciences, University of Mohaghegh Ardabili, Ardabil, Iran.

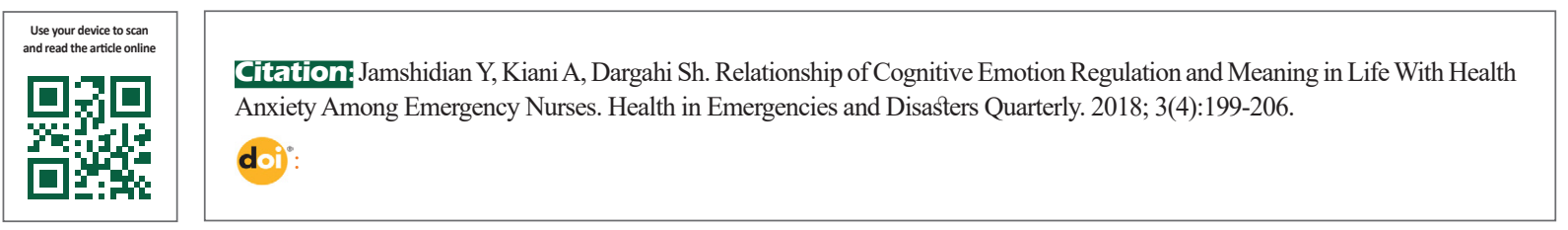

Funding: See Page 203

(c) Copyright: The Author(s)

Article info:

Received: 20 Jan. 2018

Accepted: 25 May 2018

Available Online: 01 Jul. 2018

\section{Keywords:}

Life, Health, Anxiety, Emotion, Nurses

\begin{abstract}
A B S T RACT
Background: The current study aimed to investigate the relationship of cognitive emotion regulation and meaning in life with health anxiety in nurses working in emergency department.

Materials and Methods: It was a descriptive research in the form of correlation and prediction. The sample included 100 emergency nurses in Sari City, Iran selected by randomized method of sampling. The participants completed items of the Cognitive Emotion Regulation Questionnaire (CERQ), the Meaning in Life Questionnaire (MLQ) and health anxiety questionnaire. The research data were analyzed by descriptive statistics indices, Pearson correlation analysis, Partition coefficient, and multivariate regression, using SPSS.
\end{abstract}

Results: The results suggested a significant relationship between cognitive emotion regulation and health anxiety, especially in the subscale of rumination in terms of negative cognitive emotion regulation. Also, there was a significant relationship between meaning in life and health anxiety.

Conclusion: Generally, findings of this research can be useful in future studies regarding the effect of meaning in life and cognitive emotion regulation on health anxiety.

\section{Introduction}

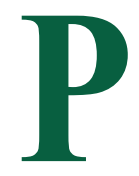

rofession has a determinant role in the mental health of each individual. Nurses are always facing with many stressors in the workplace. The nature of this job is associated with a combination of roles and responsibilities such as technical activities, professional skills, human relationships, and sympathy [1]. Health professionals reported that the emergency nurses have serious concerns about the nature of their job. They are exposed to serious risks and health issues through constant physical contact with patients and frequent use of healthcare equipment [2]. Therefore, due to the sensitivity of the occupational responsibilities of emergency nurses and their continuous interaction with patients, they are always exposed to physical and psychological stresses and illnesses [3]. 
An important factor affecting the emergency nurses who experience the highest levels of stress, is health anxiety. Health anxiety, the fear or conviction of suffering from a severe disorder, represents a dimensional and multifactorial construct consisting of cognitive, behavioral, affective, and perceptual components [4]. Health anxiety is a continuum concept which was first proposed by Salkovskis and Warwick (2001). The severity of this condition could vary from mild concerns about health problems to a self-immolation disorder characterized by extreme and sometimes delusional fears about health and physical symptoms [5].

As mentioned above, health anxiety consists of affective, cognitive, behavioral, and perceptual components. The affective component includes health concerns; the cognitive component refers to a strong belief in having a disorder, contrary to medical evidence; behavioral component includes assertive behaviors to reduce fear of diseases; and the perceptual component involves distressing preoccupation with bodily processes and sensations [6].

Health anxiety or as it is medically known, hypochondriasis is a disorder of extreme internal vigilance [7], an excessive referral to the treatment centers, and an extreme fear of death [8]. A severe health anxiety leads to reassuring behaviors about health (including referral to a physician) and circulating between health improvement and denial of the disease [9]. Myers et al. [10] argued that depression and stress is very high in most female nurses due to stressful events. Also, they reported that $60 \%-90 \%$ of nurses complain of some form of physical illness, in respect of the significant consequences of occupational stress.

Frankl argued that the motivating force of a human is to find meaning in life that refers to the values and goals varies depending on the situations and individuals. One of its important features is vitality in life [11]. The findings have shown that spirituality and spiritual wellbeing determine the psychological, physical and emotional well-being, and could predict the level of future happiness and psychological well-being [12]. They are the strongest predictors of mental health, psychological pressure, sleep disturbance, and psychosomatic complaints [13]. Therefore, meaning in life acts as a buffer against environmental stresses and facilitates stress coping [14]. Yek et al. showed that higher presence of meaning in life is associated with less health anxiety [15].

The role of emotions and emotion regulation cannot be ignored in hospital-related health anxiety. Health anxiety has features like inaccurate perception [16] which is a sign of negative cognitive emotion regulation. Thompson (1994) defined emotion regulation as "the intrinsic and extrinsic processes involved in evaluating, monitoring and modifying emotional reactions in order to accomplish one's goals" [17].

Martini and Busseri [18] in studying the ability of positive adaptation to the conditions, considered the ability to cognitively regulate emotions in confrontation with conflicts and pressures as the most important factors of adaptation. People with high health anxiety not only have dysfunctional beliefs about health and disease but also have frequent mental ruminations about their distress [19]. Therefore, given the importance of health anxiety in the quality of life of emergency nurses who have the highest vulnerability to severe illness and mortality, also the available literature is very limited in this area, this study attempted to investigate the relationship between cognitive emotion regulation and meaning of life, and health anxiety among emergency nurses.

\section{Materials and Methods}

This was a correlational survey study. Study population consisted of all emergency nurses in Sari City, Iran. Because of the restricted access to statistical population, a random sample of 100 individuals were selected from all hospitals in the city to increase external validity (according to reliable resources, 50 subjects are recommended for the correlation research) [20]. They completed questionnaires. All participants were informed about confidentiality of the results and informed consent was obtained from them, prior to completion of questionnaires. The collected data were analyzed by statistical tests in SPSS.

\section{Data collection tools}

\section{Cognitive Emotion Regulation Questionnaire}

A short version of the Cognitive Emotion Regulation Questionnaire (CERQ) designed by Garnefski, Kraaij, and Spinhoven (2002) was used for measuring the specific cognitive emotion regulation strategies that participants used in response to the experience of threatening or stressful life events. This version has 18 items consisting of 9 conceptually distinct subscales including selfblame, other-blame, rumination, catastrophizing, putting into perspective, positive refocusing, positive reappraisal, acceptance, and planning [21]. In the study of Hisami [22], this instrument has acceptable internal consistency by obtaining Cronbach's $\alpha$ coefficient (ranging from 0.76 to 0.92 ) and acceptable reliability by performing varimax rotation (with a correlation range of 0.32 to 0.67 ) and criterion validity [22]. 


\section{The Meaning in Life Questionnaire}

We also used the Meaning in Life Questionnaire (MLQ) designed by Frazier, Oishi and Kaler (2006). It has 10 items and measures two dimensions of meaning in life: presence of meaning and search for meaning. It is based on a 7-point Likert-type scale ranging from 1 (completely agree) to 7 (completely disagree). It has an acceptable internal consistency and reliability [23].

\section{Short Health Anxiety Inventory}

The Short Health Anxiety Inventory (SHAI) was used to measure health anxiety in participants. It has 18 items based on a 4-point Likert-type scale which measures worry about health, awareness of bodily sensations or changes, and fear consequences of having an illness. Items for this scale are scored from 0 to 3 . The highest scored item would be considered, if more than one item was selected [19]. The SHAI has an acceptable internal consistency ranging from $71 \%$ to $95 \%$. It also has an acceptable reliability $(85 \%)$ [19].

\section{Results}

The results presented in Table 1 indicate a negative significant relationship between cognitive emotion regulation and health anxiety $(\mathrm{r}=-0.76, \mathrm{P}<0.01)$. According to the subscales of cognitive emotion regulation, self-blaming $(\mathrm{r}=-0.45, \mathrm{P}<0.01)$, other-blaming $(\mathrm{r}=-0.38, \mathrm{P}<0.01)$, rumination $(\mathrm{r}=-0.55, \mathrm{P}<0.01)$, and catastrophizing $(\mathrm{r}=0.40, \mathrm{P}<0.01)$ had a significant negative relationship with health anxiety, while acceptance $(\mathrm{r}=0.31, \mathrm{P}<0.01)$, positive refocusing $(\mathrm{r}=0.26, \mathrm{P}<0.01)$, planning $(\mathrm{r}=0.37$, $\mathrm{P}<0.01)$, positive reappraisal $(\mathrm{r}=0.34, \mathrm{P}<0.01)$, and putting into perspective $(\mathrm{r}=0.33, \mathrm{P}<0.01)$ had a significant positive relationship with health anxiety.

Results of Table 2 indicate that the meaning in life has a significant negative relationship with health anxiety $(r=0.77, \mathrm{P}<0.01)$. According to the results of Table $3,24 \%$ of the variance in health anxiety is predictable based on cognitive emotion regulation and meaning in life. $F$ value indicates that the regression of health anxiety is statistically significant based on cognitive emotion regulation and meaning in life. Cognitive emotion regu-

Table 1. Pearson correlation coefficients between cognitive emotion regulation and health anxiety

\begin{tabular}{|c|c|c|c|c|c|c|c|c|c|c|c|}
\hline Items & $1 * *$ & 2 & 3 & 4 & 5 & 6 & 7 & 8 & 9 & 10 & 11 \\
\hline Total & 1 & & & & & & & & & & \\
\hline Self-blame & $0.71^{* *}$ & 1 & & & & & & & & & \\
\hline Other-blame & $0.78^{* *}$ & $0.42^{* *}$ & 1 & & & & & & & & \\
\hline Rumination & $0.82^{* *}$ & $0.0^{*}$ & $0.30^{*}$ & 1 & & & & & & & \\
\hline Catastrophizing & $0.79^{* *}$ & $0.35^{*}$ & 22.0 & $0.41^{* *}$ & 1 & & & & & & \\
\hline Acceptance & $0.73^{* *}$ & $0.35^{* *}$ & $0.30^{* *}$ & $0.39^{* *}$ & $0.33^{* *}$ & 1 & & & & & \\
\hline Positive refocusing & $0.91^{* *}$ & $0.26^{*}$ & 0.30 & 0.23 & $0.35^{* *}$ & $0.38^{*}$ & 1 & & & & \\
\hline Planning & $0.82^{* *}$ & $0.21^{*}$ & $0.28^{* *}$ & 0.18 & $0.37^{*}$ & 0.27 & $0.29^{*}$ & 1 & & & \\
\hline Positive reappraisal & $0.85^{* *}$ & $0.38^{* *}$ & $0.36^{*}$ & 0.31 & $0.38^{*}$ & $0.39^{* *}$ & 0.20 & $0.30^{*}$ & 1 & & \\
\hline $\begin{array}{l}\text { Putting into } \\
\text { perspective }\end{array}$ & $0.83^{* *}$ & $0.40^{* *}$ & 0.29 & $0.28^{* *}$ & 0.24 & $0.27^{* *}$ & $0.31^{*}$ & 0.41 & $0.31^{*}$ & 1 & \\
\hline Health anxiety & $-0.76^{* *}$ & $0.45^{* *}$ & $0.38^{*}$ & $0.55^{* *}$ & $0.40^{* *}$ & $-0.31^{*}$ & -0.26 & $-0.37^{* *}$ & $-0.34^{*}$ & -0.30 & 1 \\
\hline $\mathrm{P}<0.05$, **: $\mathrm{P}<$ & & & & & & & & \multicolumn{4}{|c|}{$\begin{array}{l}\text { Hilealth in } \\
\text { Emergencies and D]isasters [Oluarter }\end{array}$} \\
\hline
\end{tabular}

Table 2. Pearson correlation coefficients between meaning in life and health anxiety

\begin{tabular}{lcc}
\hline \multicolumn{1}{c}{ Variables } & $\mathbf{r}$ & Sig. \\
\hline Meaning in life and health anxiety & $-0.77^{* *}$ & 0.000 \\
\hline$* *: P<0.01$ & & $\begin{array}{l}\text { Hitealth in } \\
\text { Emergencies and |D]isasters [Oluarterly }\end{array}$
\end{tabular}


Table 3. Results of regression analysis to health anxiety based on Predictor variables

\begin{tabular}{|c|c|c|c|c|c|c|}
\hline Model & $\mathbf{R}$ & $\mathbf{R}^{2}$ & Adjusted $\mathrm{R}^{2}$ & \multicolumn{2}{|r|}{$\mathbf{F}$} & Sig. \\
\hline \multirow[t]{2}{*}{1} & 0.49 & 0.24 & 0.21 & \multicolumn{2}{|r|}{8.08} & 0.01 \\
\hline & \multicolumn{3}{|c|}{ Coefficients } & & & \\
\hline \multirow{2}{*}{ Criterion Variable } & \multicolumn{3}{|c|}{ Unstandardized Coefficients } & \multicolumn{3}{|c|}{ Standardized Coefficients } \\
\hline & Predictors & B & Standard Error & $\beta$ & $\mathbf{t}$ & Sig. \\
\hline \multirow{3}{*}{ Health anxiety } & Constant & 38.01 & 4.31 & - & 8.81 & 0.01 \\
\hline & $\begin{array}{l}\text { Cognitive emotion } \\
\text { regulation }\end{array}$ & -0.36 & 0.15 & -0.25 & -2.40 & 0.05 \\
\hline & Meaning in life & -0.29 & 0.11 & -0.23 & -2.63 & 0.50 \\
\hline
\end{tabular}

lation $(\beta=-0.25, \mathrm{t}=-2.40, \mathrm{P}<0.05)$ and meaning in life $(\beta=-0.23, \mathrm{t}=-2.63, \mathrm{P}<0.05)$ can significantly negatively predict health anxiety.

Beta values indicate that cognitive emotion regulation has more predictive power compared to the meaning in life.
Based on the results presented in Table 4, 37\% of the variance in health anxiety is predictable based on subscales of cognitive emotion regulation. $F$ value indicates that the regression of health anxiety is statistically significant, based on all dimensions. Self-blaming $(\beta=0.17, \mathrm{t}=-2.91, \mathrm{P}<0.05$, ) other-blaming $(\beta=-0.10, \mathrm{t}=-$ $2.25, \mathrm{P}<0.05)$, rumination $(\beta=0.20, \mathrm{t}=-2.42, \mathrm{P}<0.05)$,

Table 4. Results of regression analysis to health anxiety based on dimensions variable

\begin{tabular}{|c|c|c|c|c|c|c|c|}
\hline Model & $\mathbf{R}$ & $\mathbf{R}^{2}$ & \multicolumn{2}{|c|}{ Adjusted $\mathrm{R}^{2}$} & $\mathbf{F}$ & \multicolumn{2}{|c|}{ Sig. } \\
\hline \multirow[t]{4}{*}{1} & 0.61 & 0.37 & \multicolumn{2}{|c|}{0.32} & 9.12 & \multicolumn{2}{|c|}{0.01} \\
\hline & & \multicolumn{6}{|c|}{ Coefficients } \\
\hline & & \multicolumn{3}{|c|}{ Unstandardized Coefficients } & \multicolumn{3}{|c|}{ Standardized Coefficients } \\
\hline & Predictors & & B & Std. error & $\beta$ & T & Sig. \\
\hline \multirow{10}{*}{ Health anxiety } & Constant & & 41.05 & 6.17 & - & 6.65 & 0.01 \\
\hline & Self-blame & & 0.35 & 0.12 & 0.17 & 2.91 & 0.05 \\
\hline & Other-blame & & 0.18 & 0.08 & 0.10 & 2.25 & 0.05 \\
\hline & Rumination & & 0.34 & 0.14 & 0.20 & 2.42 & 0.05 \\
\hline & Catastrophizing & & 0.11 & 0.10 & 0.02 & 1.10 & 0.17 \\
\hline & Acceptance & & -0.28 & 0.11 & -0.16 & -2.54 & 0.05 \\
\hline & Positive refocusing & & -0.21 & 0.09 & -0.07 & -2.33 & 0.05 \\
\hline & Planning & & -0.27 & 0.19 & -0.16 & -1.42 & 0.21 \\
\hline & Positive reappraisal & & -0.26 & 0.11 & -0.15 & -2.36 & 0.05 \\
\hline & Putting into perspective & & -0.12 & 0.10 & -0.18 & -1.20 & 0.12 \\
\hline
\end{tabular}


acceptance $(\beta=-0.16, \mathrm{t}=-2.54, \mathrm{P}<0.05)$, positive refocusing $(\beta=-0.07, \mathrm{t}=2.33, \mathrm{P}<0.05)$, and positive reappraisal $(\beta=0.15, \mathrm{t}=2.36, \mathrm{P}<0.05)$, can significantly and negatively predict health anxiety. Also. According to beta values, rumination had the highest predictive power.

\section{Discussion}

This study attempted to assess the relationship between cognitive emotion regulation and meaning in life, and health anxiety among emergency nurses. Results show that meaning in life has significant negative relationship with health anxiety. This is consistent with the findings of Dehghani et al. [24] and Shiah and associates [25]. Yek et al. [15] also showed that higher presence of meaning in life was associated with less health anxiety. Health anxiety is common among health-related stressful occupations and leads to high economic costs imposed on healthcare receivers [26].

Studies show that people whose lives have a greater meaning can better cope with the anxieties and challenges of life; processing new information is easier for them; and they have a wider and more positive perspective of their future lives. Having meaning in life is a useful coping skill that enables people to enjoy good times and endure bad times [27].

Purposeful work and activities are one way to achieve meaning in life. For emergency nurses who work in the critical and primary care units and help patients and their colleagues, the sense of meaningfulness and being positive helps them to understand a meaningful life and its purposefulness, cope with any difficulty in this vital job, and recognize the value of their practice beyond the routine task. Therefore, the meaning in life will help a person to confront and accept difficulties and anxieties by giving meaning to any suffering and painful situation.

Results of this study also reveal that cognitive emotion regulation has a significant association with health anxiety. Among its positive and negative dimensions, "rumination" had the highest predictive power. This is in agreement with the results of Görgen et al. [4] study who reported significant and consistent associations between cognitive, behavioral, and affective dimensions of health anxiety, and dysfunctional coping and emotion regulation strategies (especially rumination, catastrophizing and other-blame) [4].

Successful cognitive emotion regulation is linked to health outcomes, interpersonal relationships, desirable job performance, and academic excellence. On the con- trary, the occurrence of problems in emotional regulation is related to mental disorders [27].

Also, people who are unable to properly manage their emotions against everyday events suffer from most of the diagnostic signs of internalizing disorders such as depression and anxiety [27], as studies have shown that rumination and catastrophizing have association with the anxiety syndrome [28]. On the whole nurses with negative emotional cognitive regulation especially a negative cognitive and perceptual insight towards themselves and their job with constant catastrophic thoughts and negative ruminations, are more prone to anxiety in the field of healthcare.

\section{Conclusion}

One of the limitations of this study was the similar age range, educational, occupational and cultural conditions of all participants, as well as the use of a sole questionnaires for data collection. Further research is suggested to conduct the same subject on other age, educational, occupational and cultural groups, and considering both interviews and questionnaire for data gathering. This study revealed the relationship between meaning in life, cognitive emotion regulation, and health anxiety, and can be useful for future studies on this area and other health-related issues.

\section{Ethical Considerations}

\section{Compliance with ethical guidelines}

All ethical principles were considered in this article. The participants were informed about the purpose of the research and its implementation stages; They were also assured about the confidentiality of their information; Moreover, They were allowed to leave the study whenever they wish, and if desired, the results of the research would be available to them.

\section{Funding}

This research did not receive any specific grant from funding agencies in the public, commercial, or not-forprofit sectors.

\section{Conflict of interest}

The authors certify that they have no affiliation with or involvement in any organization or entity with any financial interest, or non- financial interest in the subject matter or materials dismissed in this manuscript. 


\section{Acknowledgments}

The authors would like to thank all nurses who kindly participated in this study.

\section{References}

[1] Anoosheh M, Zarkhas S, Faghihzaeh S, Vasimoradi M. [Nurse-patient communication barriers in Iranian nursing (Persian)]. International Nursing Review. 2009; 56(2):243-9. [DOI:10.1111/j.1466-7657.2008.00697.x] [PMID]

[2] Moustaka E, Constantinidis TC. Sources and effects of work-related stress in nursing. Health Science Journal. 2010; 4(4):210-6.

[3] Berland A, Natvig GK, Gundersen D. Patient safety and job-related stress: A focus group study. Intensive and Critical Care Nursing. 2008; 24(2):90-7. [DOI:10.1016/j. iccn.2007.11.001] [PMID]

[4] Görgen SM, Hiller W, Witthöft M. Health anxiety, cognitive coping, and emotion regulation: A latent variable approach. International Journal of Behavioral Medicine. 2014; 21(2):364-74. [DOI:10.1007/s12529-013-9297-y] [PMID]

[5] Hosseini Ghomi T, Salimi Bajestani H, Zakeri N. [Relationship religious orientation and hope with health anxiety among women nurses in Imam Khomeini hospital of Tehran (Persian)]. Iranian Journal of Nursing Research. 2014; 9(1):17-24.

[6] Longley SL, Watson D, Noyes R. Assessment of the hypochondriasis domain: The Multidimensional Inventory of Hypochondriacal Traits (MIHT). Psychological Assessment. 2005; 17(1):3-14. [DOI:10.1037/1040-3590.17.1.3] [PMID]

[7] Abramowitz JS, Deacon BJ, Valentiner DP. The Short Health Anxiety Inventory: Psychometric Properties and Construct Validity in a Non-clinical Sample. Cognitive Therapy and Research. 2007; 31(6):871-83. [DOI:10.1007/ s10608-006-9058-1]

[8] Noyes R, Stuart SP, Langbehn DR, Happel RL, Longley S, Muller BA, et al. Test of an interpersonal model of hypochondriasis. Psychosomatic Medicine. 2003; 65(2):292-300. [DOI:10.1097/01.PSY.0000058377.50240.64] [PMID]

[9] Salkovskis PM, Warwick HM. Making sense of hypochondriasis: a cognitive theory of health anxiety. In: Asmundson G, Taylor S, Cox BJ, editors. Health Anxiety: Clinical and Research Perspective on Hypochondriasis and Related Conditions. Hoboken, New Jersey: John Wiley \& Sons; 2001.

[10] Myers WC, Burket RC, Lyles WB, Stone L, Kemph JP. DSM-III diagnoses and offenses in committed female juvenile delinquents. The Bulletin of the American Academy of Psychiatry and the Law Online. 1990; 18(1):47-54. [PMID]

[11] Frankl VE. The will to meaning: Principles and application of Logo therapy. New York: World Publishing; 1969.

[12] Rowold J. Effects of Spiritual Well-Being on Subsequent Happiness, Psychological Well-Being, and Stress. Journal of Religion and Health. 2011; 50(4):950-63. [DOI:10.1007/ s10943-009-9316-0] [PMID]

[13] Martínez B, Custódio RP. Relationship between mental health and spiritual wellbeing among hemodialysis patients: A correlation study. Sao Paulo Medical Journal. 2014; 132(1):23-7. [DOI:10.1590/1516-3180.2014.1321606] [PMID]

[14] Krause N. Evaluating the stress-buffering function of meaning in life among older people. Journal of Aging and Health. 2007; 19(5):792-812. [DOI:10.1177/0898264307304390] [PMID]

[15] Hwei Yek M, Olendzki N, Kekecs Z, Patterson V, Elkins G. Presence of meaning in Life and Search for Meaning in Life and Relationship to Health Anxiety. Psychological Reports. 2017; 120(3):383-90. [DOI:10.1177/0033294117697084]

[16] Salkovskis PM, Rimes KA, Warwick HM, Clark DM. The health anxiety inventory: Development and validation of scales for the measurement of health anxiety and hypochondriasis. Psychological Medicine. 2002; 32(5):843-53. [DOI:10.1017/S0033291702005822] [PMID]

[17] Dillon DG, Ritchey M, Johnson BD, LaBar KS. Dissociable effects of conscious emotion regulation strategies on explicit and implicit memory. Emotion. 2007; 7(2):345-62. [DOI: 10.1037/1528-3542.7.2.354] [PMID]

[18] Martini TS, Busseri MA. Emotion regulation strategies and goals as predictors of older mothers' and adult daughters' helping related subjective well-being. Psychology and Aging. 2010; 25(1):48-59. [DOI:10.1037/a0018776] [PMID]

[19] Eastin MS, Guinsler NM. Worried and wired: Effects of health anxiety on information-seeking and health care utilization behaviors. CyberPsychology \& Behavior. 2006; 9(4):494-8. [DOI:10.1089/cpb.2006.9.494] [PMID]

[20] Delaware A. [Theoretical principles and practical research in the humanities and social sciences (Persian)]. Tehran: Roshd; 2001.

[21] Garnefski N, Kraaij V, Spinhoven P. Negative life events, cognitive emotion regulation, and emotional problems. Personality and Individual Differences. 2001; 30(8):1311-27. [DOI:10.1016/S0191-8869(00)00113-6]

[22] Hisami J. The psychometric properties of the Cognitive Emotion Regulation Questionnaire (CERQ). Journal of Clinical Psychology. 2011; 2(3):73-83.

[23] Steger MF, Fitch-Martin AR, DonnellyJ, Rickard KM Meaning in life and health: Proactive health orientation links meaning in life to health variables among American undergraduates. Journal of Happiness Studies. 2015; 16(3):583-97. [DOI:10.1007/s10902-014-9523-6]

[24] Dehghani T, Yarahmadi R, Taghdisi MH, Daneshvar R, Ahmadpour J. [The relationship between meaning in life and depression, anxiety and stress status among college students of Iran university of medical sciences in 2013 (Persian)]. Iranian Journal of Health Education and Health Promotion. 2013; 1(3):83-92.

[25] Shiah YJ, Chang F, Chiang SK, Lin IM, Carl Tam WC. Religion and health: Anxiety, religiosity, meaning of life and mental health. Journal of Religious Health. 2015; 54(1):3545. [DOI:10.1007/s10943-013-9781-3] [PMID] 
[26] Sunderland M, Newby JM, Andrews G. Health anxiety in Australia: Prevalence, comorbidity, disability and service use. British Journal of Psychiatry. 2013; 202(1):56-61. [DOI:10.1192/bjp.bp.111.103960]

[27] Aldao A, Nolen-Hoeksema S, Schweizer S. Emotionregulatin stragies across psychopathology: A meta- analytic review. Clinical Psychology Review. 2010; 30(1):217-37. [DOI:10.1016/j.cpr.2009.11.004] [PMID]

[28] Chan SM, Chan SK, Kwok WW. Ruminative and catastrophizing cognitive styles mediate the association between daily hassles and high anxiety in Hong Kong adolescents. Child Psychiatry \& Human Development. 2015; 46(1):57-66. [DOI:10.1007/s10578-014-0451-9] 
